belly of the muscle, the latter was freshened transversely for its whole width with a sharp scalpel, by scraping it. Then the upper end of the tarsus was exposed exactly to the extent of the width of the muscle, and by means of three silk sutures, one taking in the central fibres of the muscle, the other two taking in the two edges, the whole width of the superior rectus muscle was firmly sutured to the tarsus. This fixes the central and nasal portions of the eyelid, but should the lateral part still sag, a point of attachment between the edge of the tarsus and the sclera can be added then and there, or later.

The lagophthalmos present immediately after operation does not last long, so it is not necessary to sew the edges of the eyelids together for a couple of days as I did. I left the sutures in place, as they did not irritate. I did not evert the lid for one month so as to run no risk of loosening the attachments. Firm union had set in, perfect $c u l-d e-s a c$, without pockets for retention of secretions, and no trace of the sutures.

November is gone, I have seen the case once a month. All disfigurement is gone and movements are quite free, even blinking, for they have of course been religiously eliminated in front of the looking-glass. The trick of the brow persisted longest. It was still present at the end of October, and gave the impression only of being a quaint mannerism. It has now ceased entirely.

A persistent flush and lacrimation puzzled us, but was easily explained, when, exactly four months after operation, a suture made its appearance. In future I suggest bringing the three central, and also the lateral stitch, if one be used, through on to the outer surface of the eyelid, and tying them over glass beads.

The eye quieted down completely, all lacrimation has ceased, and now, May, 1924, the functional result and the appearance are excellent.

\title{
A CASE OF ECTOPIA LENTIS WITH COLOBOMA*
}

\section{BY \\ D. V. GIRI \\ EASTBOURNE}

Horace B, aged 11, came under my observation as an out-patient at the Eastbourne Eye Infirmary on February 2, 1918.

The mother of the boy was unaware of his defective vision until she was advised by the school authorities to have his eyes seen to. A horizontal scar in the middle of the patient's forehead was caused

* Shown at the Annual Congress of the Ophthalmological Society of the United Kingdom in 1918. 
by a fall in infancy. It appears the eyes were unaffected by the fall. The head was badly moulded. There was no history of difficult labour or instrumentation during delivery. The patient was the youngest of a family of eight children; all the others were said to have good eyes. There was no history of "bad eyes" either on the father's or on the mother's side.

The boy was nervous and given to jerky movements of the head.

Both eyes showed marked irido-donesis. Any difference in depth between one part and another of the anterior chambers could not be made out. The eyes looked normal in size and appearance. Pupils equal and active.

Lenses.-With undilated pupils the ophthalmoscope revealed the outer edges of the lenses which were displaced obliquely inward. Under mydriasis the visible outer contour of the lenses showed an angular notch in each lens, the right lens being notched below and the left above which showed two angles, though less

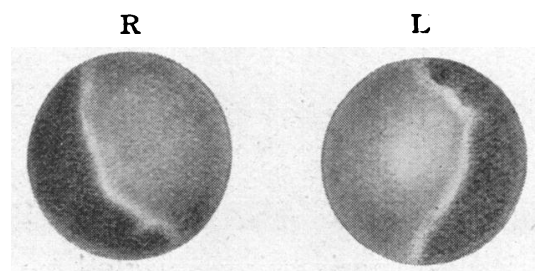

Magnified about 2 diameters. The lightly shaded parts represent the lenses.

pronounced than in the right. There was no apparent movement of the lenses with movements of the head. Even bending the head forward did not appear to alter their position. The lenses were clear.

I could not make out the zonular fibres in the aphakic area and. it is said that in most cases they are almost wholly absent in that area. Though in view of this fact, the lenses may be expected to move when the head moves, at any rate in instances in which the intact zonular fibres cover only half or less than half the circumference of the lens, to my knowledge there is no record of movement having been looked for in previous cases.

The eyes were parallel. The refraction of the phakic area was about $-12 \mathrm{D}$ and that of the aphakic area about $+8 \mathrm{D}$ with which by direct ophthalmoscopy the discs and a fair amount of the adjoining background were clearly seen to be healthy.

R.V. $<5 / 60$; L.V. $<5 / 60$; not improved with glasses.

In this case there was no concomitant congenital anomaly, such as coloboma of the iris, corectopia, etc.

According to Parsons only two cases have been recorded of ectopia lentis with coloboma, one by Rogman, in which the lenses 
were displaced downwards, and one by Marcus Gunn, in which the ectopia was upwards. The present case differs from them in that the displacement was obliquely inwards and the defects in the lenses were at opposite extremities of the exposed contours.

It was not merely as a clinical curiosity that I brought this case before the Congress. Seeing that there was no nystagmus and no squint, that the eyes were normal in appearance, the fundi healthy and the only chance of improving the vision, so far as I could see, consisted in needling the lenses and prescribing suitable glasses, I was inclined to render the eyes aphakic. As I was not aware of any instance of the kind where the suggested procedure had been adopted I wished to hear of such from the members of the Congress.

At the Congress one of the members stated that he had rendered the eyes aphakic in similar cases and obtained improvement of vision with correcting glassés. I have discovered since that $\mathrm{Mr}$. Charles Wray had written a paper on discission in cases of ectopia lentis. In the above case I had to needle the lenses eight times altogether before they were completely absorbed. One needling proved sufficient in the case of the right lens, but the left lens required no less than seven discissions owing to the repeated closing of the capsule after the absorption of a few flakes actually released at the operation or protruding through the opening every time. The first needling of both lenses was done on February 17, 1918, the last needling of the left lens on February 16, 1919, its absorption becoming complete by February 26, 1919. On the latter date he was refracted and

R.V. $\bar{c}+12 \mathrm{D}$ sph. $+1 \mathrm{D}$ cyl. ax. $120^{\circ}$ up and out was $5 / 24$.

L.V. $\bar{c}+13 \mathrm{D}$ sph. $+2 \mathrm{D}$ cyl. ax. $60^{\circ}$ up and out $5 / 24$; binocularly $5 / 18$ partly.

The patient was last seen by Mr. G. B. Lowe on December 31, 1923 , nearly five years after the aphakic eyes were corrected. The refraction was found to be unchanged and with the original corrrection R.V. was $6 / 24$ and L.V. 6/24. This leads one to think that in this case at any rate the growth of the eyes was complete at 11 years of age. A form of amblyopia was present in them and it was either already too late to acquire normal acuity of vision even with correction or there was an inherent incapacity to develop it.

Amblyopia of this kind has to be put in a class by itself. According to Worth both congenital amblyopia and amblyopia ex anopsia are uniocular, the one being attributed to suppression of the image in the squinting eye and the other to an inherent incapacity of an apparently healthy eye to acquire normal acuity of vision in the absence of squint and no matter how early any refractive error is corrected. The poor vision in ectopia lentis 
concerns both eyes; whether this is to be classed as congenital or acquired can only be decided by a careful study of cases of ectopia lentis rendered aphakic very early in life and optically corrected, e.g. within the first year of life. If the child is found to develop normal acuity of vision the amblyopia may be classed as acquired; otherwise as congenital. If the evidence is for the amblyopia being acquired, the study of older cases rendered aphakic and corrected will reveal up to what age the macular region retains the capacity to preponderate and attain normal acuity.

\title{
REFERENCES
}

Parsons.- " Pathology of the Eye," Vol. III, p, 809.

Claud Worth.- " Squint," 3rd edition, 1906.

\section{A CASE OF CONGENITAL MIOSIS}

BY

\author{
Thomas H. Cresswell, D.O.(Oxon.)
}

LiNCOLN

A RECENT paper by S. Holth and O. Berner on congenital miosis appeared in this journal (Brit. Jl. of Ophthal., p. 401, 1923). A patient in whom this abnormality was present has recently come under my observation at the County Hospital, Lincoln, and was shown at a meeting of the Midland Ophthalmological Society.

The patient was a man of 57 years of age, one of a family of seven. He knew that his eyes were peculiar and also that he was the only member of his family so affected. He added that when nine months old he suffered from smallpox and that his mother had suggested that the condition of his eyes might be due to this disease. At the same time that he had smallpox he had had several severe abscesses on the top of the head. These have left several deep star-shaped scars into which it is possible to insert the tip of the finger and which are adherent to the calvarium. The possibility of these scars being the result of specific gummatous periostitis has not been lost sight of, but receives no support from the patient's family and personal history or general condition. He had always considered that he had good sight, had no difficulty in going about at night and had never suffered from headaches.

On examination the pupils did not react to light nor to convergence. Seen through a loupe there was possibly a very faint movement of the pupillary margin on exposure to a bright light. Both pupils were roughly circular in shape. Their sizes with and without mydriatics were as follow: 